\title{
Introducing IJTMB's Trigger Points: Topical Dialogue amongst Therapeutic Massage \& Bodywork Practitioners and Educators
}

\author{
Whitney Lowe, LMT, ${ }^{1}$ Education Section Editor, IJTMB, Niki Munk, PhD, LMT, ${ }^{2}$ Practice \\ Section Editor, IJTMB, and Antony Porcino, PhD, HSI, ${ }^{3 *}$ Executive Editor, IJTMB \\ ${ }^{1}$ Director, OMERI, Sisters, OR, USA; ${ }^{2}$ Department of Health Sciences, Indiana University - IUPUI, Indianapolis, IN, USA; \\ ${ }^{3}$ Complementary Medicine Education and Outcomes Research Program, British Columbia Cancer Agency, Vancouver, \\ $B C$, Canada
}

The International Journal of Therapeutic Massage and Bodywork (IJTMB) has as its core a key interest in and mission to develop the practice of therapeutic massage and bodywork by contributing to the field's body of knowledge. The IJTMB Editorial Board understands that one's daily practice provides the initial testing ground for the development of practice-based knowledge and, ultimately, expertise. Consequently, this practicebased knowledge and experience provides fertile ground for research ideas that further refine our understanding and come full circle to enhance clinical efficacy. Ultimately, without discourse and knowledge transference, the possibility of growing the body of knowledge for therapeutic massage and bodywork or stimulating research in the field is lost. To facilitate discourse and transference of knowledge within the field of therapeutic massage and bodywork, the IJTMB is launching a new journal component entitled Trigger Points: Topical Dialogue amongst Therapeutic Massage \& Bodywork Practitioners and Educators. The purpose of IJTMB's Trigger Points is to "trigger" the sharing and discussion of knowledge and expertise among therapeutic massage and bodywork practitioners, educators, and researchers about different approaches to treating specific conditions or addressing specific population issues. Each IJTMB issue, starting with this issue, will include a call for responses to the next Trigger Points topic. Publication of the results for each topic will be in the second issue after the initial call for submissions. With your participation, these IJTMB Trigger Points columns will spark dynamic dialogue, perhaps even collaborations, in the therapeutic massage and bodywork field across practitioners, educators, and researchers.

\section{KEYWORDS: editorial; knowledge translation}

The International Journal of Therapeutic Massage and Bodywork (IJTMB) has, as its core, a key interest in and mission to develop the practice of therapeutic massage and bodywork by contributing to the field's body of knowledge. As an open-access journal, IJTMB seeks to accomplish this through the publication of therapeutic massage and bodywork research and knowledge-based discourse. The IJTMB Editorial Board understands that not all substantive knowledge comes from study-based research. Indeed, one's daily practice provides the initial testing ground for the development of practice-based knowledge and, ultimately, expertise. Consequently, this practice-based knowledge and experience provides fertile ground for research ideas that further refine our understanding and return to enhance clinical efficacy.

When carefully noted, discussed with colleagues, and grounded in a field's treatment theory ${ }^{(1)}$, practicebased knowledge and experience is a key component to that field's body of knowledge. The important translational aspect of this practice-informs-body-ofknowledge concept is that a freely accessible gathering place is needed to accumulate and examine what is happening in practice across a variety of practitioners, settings, approaches, and techniques. This gathering of information needs to be organized and structured in such a way that supports and encourages (a) the use of the presented information in practice, education, and research, and (b) critical discussion about the merits, justification, and reasoning behind such practicebased knowledge components. In the massage field, mediums for this sort of exchange are limited due in part to (a) the high variability in treatment approach, education, and credentialing, (b) few field-specific publications, and (c) a general lack of discussion opportunities and communication across and between practitioners, educators, and researchers in the field. Ultimately, without discourse and knowledge transference, the possibility of growing the body of knowledge for therapeutic massage and bodywork or stimulating research in the field is lost. To facilitate discourse and transference of knowledge within the field of therapeutic massage and bodywork, the IJTMB is launching a new journal component entitled Trigger Points: Topical Dialogue amongst Therapeutic Massage \& Bodywork Practitioners and Educators. 
The purpose of IJTMB's Trigger Points is to "trigger" the sharing and discussion of knowledge and expertise among therapeutic massage and bodywork practitioners, educators, and researchers about different approaches to treating specific conditions or addressing specific population issues. Each IJTMB issue, starting with this issue, will include a call for responses to the next Trigger Points topic. Responders to each Trigger Points topic will have to the end of the issuing month to submit briefs outlining how they approach the current topic within their practice or teaching environments. Depending on the approach discussed in the brief (practice or education), respondents will submit their briefs to either IJTMB's Practice or Education Section Editors, Niki Munk and Whitney Lowe, respectively. Submitted briefs for IJTMB's Trigger Points should be no longer than 250 words and include concise, yet detailed, information about how and why the responder uses particular approaches and techniques when addressing the topic in either their practice or educational setting.

Submissions should include concise, appropriate contextual information that would be needed to understand and apply the knowledge, such as population-specific details (age, gender, etc.), primary indications, key contraindications, the intention for the treatment(s) described, and any pertinent training information. If relevant to the knowledge, describe if there is a particular history to the treatment approach used or if it is based in previous research (references would be appropriate, and would not count to the word limit). Respondents should also state the practice or teaching environment (e.g., spa, physical therapy clinic, pain clinic) in which they normally use or teach the knowledge.

The IJTMB Practice and Educator Editors will review the submitted briefs, draft a synopsis that will include exemplars, and work together to provide commentary on the relevance or application of the knowledge within practice, education, and possibly research. Based on expertise, a guest editor may be selected from the submitters to assist in the synopsis and commentary development, with a brief biography about that person to be included in the edition. Some topics may illicit additional requests for submissions. Publication of the results for each topic will be in the second issue after the initial call for submissions.

With your participation, these IJTMB Trigger Points columns will spark dynamic dialogue, perhaps even collaborations, in the therapeutic massage and bodywork field across practitioners, educators, and researchers, bringing issues on the topics to light, and perhaps even triggering submissions of practice and education articles and research on the treatment theory development and articulation for the field. The significance potential for IJTMB's Trigger Points is great and we are excited to provide this opportunity to the therapeutic massage and bodywork field.

For the maiden IJTMB Trigger Points topic, we invite therapeutic massage and bodywork practitioners and educators to consider and submit briefs for hypertonicity of the quadratus lumborum muscle. Please send submissions by July 1, 2014 to the Practice Section Editor, Dr. Munk at nmunk@iu.edu or to the Education Section Editor, Mr. Lowe at wlowe97@gmail.com. Feedback about IJTMB Trigger Points is also welcome, as are suggestions for future topics.

We look forward to learning from you.

\section{COPYRIGHT}

Published under the CreativeCommons AttributionNonCommercial-NoDerivs 3.0 License.

\section{REFERENCES}

1. Whyte J, Dijkers MP, Hart T, Zanca JM, Packel A, Ferraro M, et al. Development of a theory-driven rehabilitation treatment taxonomy: conceptual issues. Arch Phys Med Rehab. 2014;95(1 Suppl):S24-32.

Corresponding author: Antony J. Porcino, BSc, $\mathrm{PhD}$, HIS, Complementary Medicine Education and Outcomes Research Program, School of Nursing, University of British Columbia, T291 - 2211 Wesbrook Mall, Vancouver, BC, Canada V6T 2B5

E-mail: eeitjmb@gmail.com 